\title{
Surface Modified Characteristics of the Tetracalcium Phosphate as Light-Cured Composite Resin Fillers
}

\author{
Wen-Cheng Chen, ${ }^{1,2}$ Chia-Ling Ko, ${ }^{1,2}$ and Chi-Jen Shih ${ }^{3}$ \\ ${ }^{1}$ Advanced Medical Devices and Composites Laboratory, Department of Fiber and Composite Materials, \\ College of Engineering, Feng Chia University, Taichung 407, Taiwan \\ ${ }^{2}$ Dental Medical Devices and Materials Research Center, College of Dental Medicine, Kaohsiung Medical University, \\ Kaohsiung 807, Taiwan \\ ${ }^{3}$ Department of Fragrance and Cosmetic Science, College of Pharmacy, Kaohsiung Medical University, Kaohsiung 807, Taiwan
}

Correspondence should be addressed to Chi-Jen Shih; cjshih@kmu.edu.tw

Received 4 June 2014; Revised 24 June 2014; Accepted 1 July 2014; Published 10 July 2014

Academic Editor: Seunghan Oh

Copyright (C) 2014 Wen-Cheng Chen et al. This is an open access article distributed under the Creative Commons Attribution License, which permits unrestricted use, distribution, and reproduction in any medium, provided the original work is properly cited.

\begin{abstract}
The objectives of this study are to characterize the properties of light-cured composite resins that are reinforced with whisker surface-modified particles of tetracalcium phosphate (TTCP) and to investigate the influence of thermal cycling on the reinforced composites properties. The characteristics of ultimate diametral tensile strength (DTS), moduli, $\mathrm{pH}$ values, and fracture surfaces of the samples with different amounts of surface-modified TTCP $(30 \%-60 \%)$ were determined before and after thermal cycling between $5^{\circ} \mathrm{C}$ and $55^{\circ} \mathrm{C}$ in deionized water for 600 cycles. The trends of all groups were ductile prior to thermal cycling and the moduli of all groups increased after thermal cycling. The ductile property of the control group without filler was not significantly affected. Larger amounts of fillers caused the particles to aggregate, subsequently decreasing the resin's ability to disperse external forces and leading to brittleness after thermal cycling. Therefore, the trend of composite resins with larger amounts of filler would become more brittle and exhibited higher moduli after thermal cycling. This developed composite resin with surface modifiedTTCP fillers has the potential to be successful dental restorative materials.
\end{abstract}

\section{Introduction}

Secondary caries and restoration fractures represent the two major shortcomings of dental restorative composite resins [1]. Composite resins consist of a polymerizable resin base and ceramic fillers to form a dental resin; they are generally composed of two or more distinct phases. As micro- and nanotechnologies continue to develop intelligent and responsive biomaterial medical restoration methods, dental composite resins are likewise progressing to prevent secondary caries and furthermore regenerate tooth structure [2]. In recent years, calcium phosphate-containing compounds have been studied as caries-inhibiting composite resin fillers due to their ability to release calcium $\left(\mathrm{Ca}^{2+}\right)$ and phosphate $\left(\mathrm{PO}_{4}{ }^{3-}\right)$ ions. Hydroxyapatite $\left[\mathrm{Ca}_{10}\left(\mathrm{PO}_{4}\right)_{6}(\mathrm{OH})_{2}\right.$, $\left.\mathrm{HA}\right]$, the structural prototype of the main mineral component of teeth and bones, is proposed to be the relative stable product in the precipitation of $\mathrm{Ca}^{2+}$ and $\mathrm{PO}_{4}{ }^{3-}$ ions. Besides, the apatite precipitate demonstrates a range of $\mathrm{pH}$ values from neutral to basic ( $\mathrm{pH} 7$ to 9 at $37^{\circ} \mathrm{C}$ ) [3]. Tetracalcium phosphate $\left[\mathrm{Ca}_{4}\left(\mathrm{PO}_{4}\right)_{2} \mathrm{O}, \mathrm{TTCP}\right]$ is a compound with a high $\mathrm{Ca} / \mathrm{P}$ atomic ratio of 2.0. TTCP exhibits higher chemical activity when reacted with an acidic solution (e.g., in an inorganic acid, with a saturated or unsaturated homopolymer, or with a copolymer of an unsaturated organic acid and physiological saline). The obtained restorative substance after reaction in situ has an affinity in living cells and is useful as an osteosynthetic material, a dental material, and so on. By adding calcium phosphate fillers to composite resins, the resins may have the potential to remineralize carious enamel and dentin lesions in vitro [4-6].

Studies have shown, however, that the mechanical strengths of dental composite resins with calcium phosphate fillers are weak; they are only useful for sealants [7]. One 
study used apatite particles combined with nanometer-scale silica whiskers as mixed filler in an attempt to overcome this loss of strength [8]. These authors found that the whiskered composite had substantially improved mechanical properties when compared to the reinforced fillers in the composite resins without whiskers $[8,9]$. Subsequently, group studies have investigated the mechanical properties and ion-releasing abilities of composite resins with TTCP and anhydrous dicalcium phosphate $\left(\mathrm{CaHPO}_{4}, \mathrm{DCPA}\right)$ separately mixed with a silica whisker filler. Composite resins with different calcium phosphate particle sizes, filler matrix mass ratios, and whisker-to-calcium phosphate particle ratios were tested under different $\mathrm{pH}$ values [10-12]. These studies found that a major advantage of using the new nanoparticles/nanowhiskers is that high levels of $\mathrm{Ca}^{2+}, \mathrm{PO}_{4}{ }^{3-}$, and $\mathrm{F}^{-}$ are released at low filler levels $(<30 \%)$ in the resin due to the high surface area of the nanoparticles. This high surface area leaves room in the resin for substantial reinforcement fillers. The combination of nanofillers with ion releasing ability may yield a nanocomposite with both stress-bearing and cariesinhibiting capabilities; however, a combination is not yet available in current materials [13-15].

While adding nanoparticles/nanowhiskers into composite resins can achieve low filler levels with strong reinforcing properties, problems may arise when these materials are used long-term in a dynamic oral environment. Typical problems are the small amount of exposed fillers becoming exhausted quickly, inhibiting mineralization, and the random clustering calcium phosphate nanoparticle defects lowering the strength of the composite resin. Studies regarding the characterization of calcium phosphates as reinforcements in composite resins through thermal cycling processes are quite sparse. One study showed that the micrometer-scale TTCP particle modification method of growing nanowhiskers on surfaces can reinforce calcium phosphate bone cement and produce improved strength when compared to nonsurfacetreated TTCP bone cement [16]. At daily conditions, teeth were thermally cycled four times at $5^{\circ} \mathrm{C} / 55^{\circ} \mathrm{C}$ and compared with the general oral condition [17-19]. The elapsed time of restorative materials after 600 cycles was estimated at approximately six months and then the restoration after testing is adequately quantified. The objectives of this study are to characterize the physical/chemical properties of composite resins with varying amounts of TTCP surface whisker pretreatments as reinforcing filler $(30 \%-60 \%)$ and to investigate the influence of 600 thermal cycles at $5^{\circ} \mathrm{C} / 55^{\circ}$ on the resincomposite properties.

\section{Materials and Methods}

2.1. Fillers Were Used to Form a Composite Resin. The nanowhisker treatment of TTCP powder surfaces was performed as previously employed [20]. Briefly, the TTCP powder filler was fabricated through the reaction of dicalcium pyrophosphate $\left(\mathrm{Ca}_{2} \mathrm{P}_{2} \mathrm{O}_{7}\right.$; Sigma Chem. Co., $\mathrm{MO}$, USA) and calcium carbonate $\left(\mathrm{CaCO}_{3}\right.$; Katayama Chem. Co., Tokyo, Japan) at a weight ratio of $1.3: 1.0$. The powders were uniformly mixed and heated to $1400^{\circ} \mathrm{C}$. Subsequently, sintering bulk was air quenched to form the TTCP phase [21]. Whiskers were formed via mixing $1 \mathrm{~g}$ TTCP powder into $13 \mathrm{~mL}$ of a $3 \mathrm{M}\left(\mathrm{NH}_{4}\right)_{2} \mathrm{HPO}_{4}$ solution at a $\mathrm{pH}$ of 8.6 for $5 \mathrm{~min}$ at room temperature. The surface nanowhiskerderived powder was vacuum-filtered, immediately washed with deionized water twice, and dried in an oven. The mean particle size decreased to $\sim 10 \mu \mathrm{m}$. The specimen was coated with a thin carbon film for transmission electron microscopy (TEM) examination. A JEOL JEM-3010 scanning TEM operated at $200 \mathrm{kV}$ was used for the study. The patterns were indexed and identified using detailed measurements and were compared with the $d$ value found in the Joint Committee on Powder Diffraction Standards (JCPDS). Known calcium phosphate phases and generated electron diffraction patterns were directly compared to the observed diffraction patterns.

2.2. Resin Compositions. The resin matrix was largely formulated with bisphenol A-diglycidyl dimethacrylate (BisGMA) and triethylene glycol dimethacrylate (TEGDMA). Other additives included light initiator camphorquinone (CQ) with dimethylaminoethyl methacrylate (DMAEMA) as the accelerator and butylated hydroxytoluene (BHT) as the photostabilizer. All chemicals were obtained from Sigma Aldrich. The composition ratio of the matrix was $48.975 \%$ Bis-GMA, 48.975\% TEGDMA, 1.0\% DMAEMA, 1.0\% CQ, and $0.05 \%$ BHT [19]. The polymer-matrix composites with TTCP whisker-treated fillers were used to form composite resins with ratios of 30, 40, 50, and $60 \mathrm{wt} \%$. Each resin composite was uniformly mixed, loaded into a $10 \mathrm{~mL}$ syringe, and covered in aluminum foil to prevent any possible reactions caused by the ambient light. The resin composites were used within $24 \mathrm{~h}$ after preparation.

2.3. Mechanical Testing. The effect of the surface whisker treatment on the strength of the resins was evaluated after preparing a sample mold with a $6 \mathrm{~mm}$ diameter opening and $3 \mathrm{~mm}$ depth [22], and a light curing process was used to generate half-filled and totally filled samples (Demetron Optilux 401, Kerr, USA) for $40 \mathrm{~s}$ each. To ensure the resin was completely cured and at the correct degree of conversion, the left and right sides of the samples were cured again after de-molding. Because diametral tensile strength (DTS) measurements have been widely used to measure the mechanical strength of bis-GMA-based composite resins in the literature [22-24], DTS values were used to express the strength of the dental resin specimens in this study. The test samples were sent for DTS testing immediately after curing $(n=$ 15). The specimens were compressed diametrically until the maximum stress was recorded or specimens were fractured, introducing tensile stress on the force application plane. The ultimate tensile strength was determined from the stressstrain curves using the formula DTS $=2 P / \pi D T$, where $P$ is the load applied, $D$ represents the diameter of the cylinder, and $T$ is the thickness of the cylinder $[23,24]$. The elasticity modulus was calculated from an inclination of an elastic part on proportionality of stress to strain curves by $\sim 2.0 \%$ offset. 

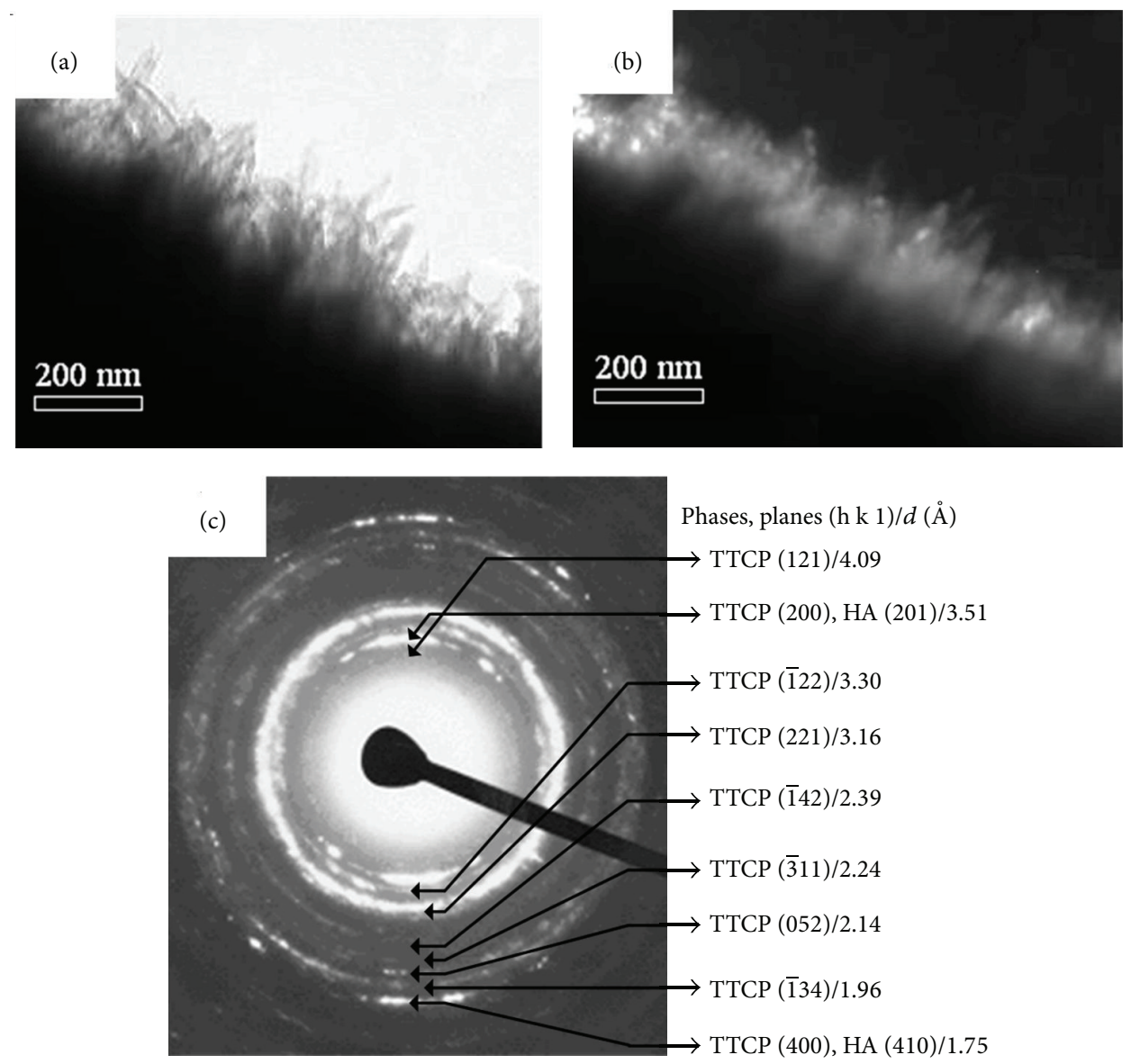

FIgURE 1: (a) Bright field, (b) dark field, and (c) diffraction pattern images of whiskers formed on the TTCP particle surfaces. All indexed rings indicate the proximity of monolithic TTCP whiskers.

2.4. Thermal Cycling. The samples were immersed at a ratio of $1 \mathrm{~g}$ sample per $10 \mathrm{~mL}$ deionized water for $24 \mathrm{~h}$ at $37^{\circ} \mathrm{C}$ to become saturated with liquid. The samples with and without filler reinforcements were then thermal cycled $(600$ cycles, $5^{\circ} \mathrm{C} / 55^{\circ} \mathrm{C}, 2 \mathrm{~min} / \mathrm{cycle}$; Long Wha Enterprise Co., Kaohsiung, Taiwan) using an immersion ratio of $1 \mathrm{~g}$ sample per $10 \mathrm{~mL}$ deionized water. The $\mathrm{pH}$ values of the immersed solutions after testing were measured immediately. The wet DTS values $(n=15)$ of the specimens with varying lengths of immersion time were measured using a desktop mechanical tester (LLOYD Instruments, Tokyo, Japan) at a crosshead speed of $2.0 \mathrm{~mm} / \mathrm{min}$.

2.5. Fracture Surface Observation. The fracture surfaces obtained from selected testing specimens were examined using a field emission scanning electron microscope (SEM; Hitachi S-3000N, Hitachi, Tokyo, Japan) to observe the dispersive and bonding conditions between the resin phase of the reinforcement and the matrix before and after thermal cycling.

2.6. Statistical Analysis. Statistical analyses of the results were primarily carried out with 1-way ANOVA. The Tukey-Kramer pairwise comparison was used to evaluate the statistical significance of the deviations in properties of the DTS values and modulus of elasticities between the control and all the test groups using JMP 8.0 software (SAS Institute, Inc., Cary, NC, USA). In all cases, the results were considered statistically different at $P<0.05$.

\section{Results}

3.1. Filler Characterization. When the powder was whiskertreated for $5 \mathrm{~min}$ in a $\left(\mathrm{NH}_{4}\right)_{2} \mathrm{HPO}_{4}$ solution, the TTCP phase remained almost unchanged. As shown with TEM, bright field (BF) and dark field (DF) (Figure 1), the surfaces of the TTCP particles were full of nanometer-sized whiskers; typical whiskers had length-to-width ratios of $>10$. Although TTCP and apatite have many crystallographic planes with similar $d$ values, the presence of diffraction patterns in the apatite phase indicates that it had a smaller chance of whisker formation than the TTCP phase. The selected area diffraction (SAD) pattern with an aperture size of $40 \mathrm{~nm}$ reveals that the radically grown whiskers have a crystal structure similar to that of TTCP (Figure 1(c)), which is typically approximately $10 \mathrm{~nm}$ to $200 \mathrm{~nm}$ long and $1 \mathrm{~nm}$ to $20 \mathrm{~nm}$ wide. 


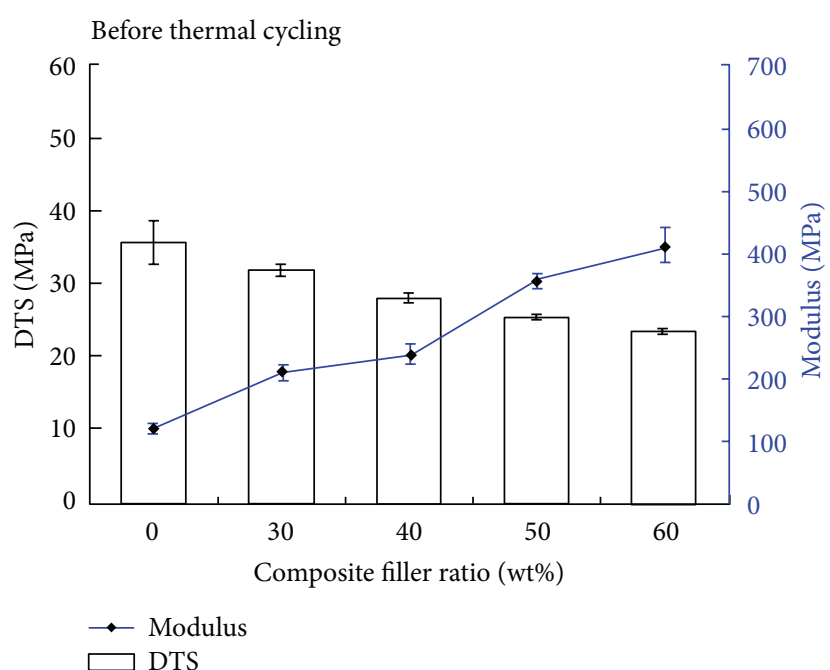

(A)

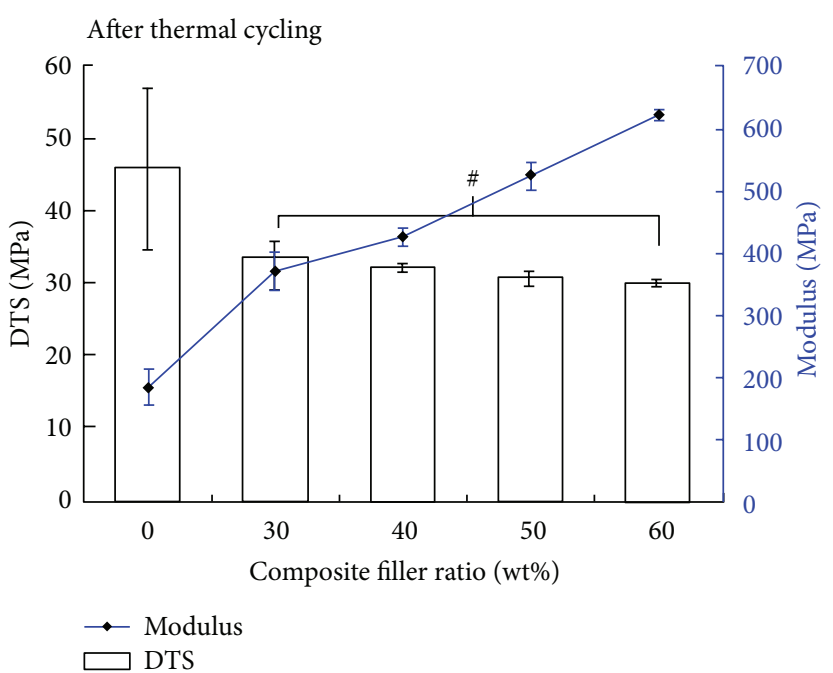

(B)

(a)

Before thermal cycling

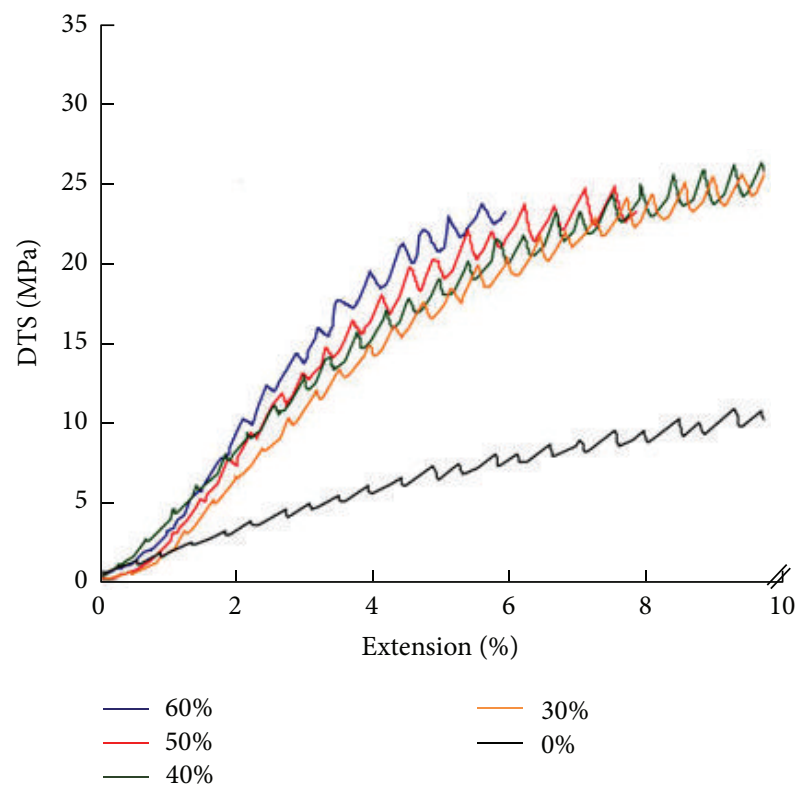

(A)

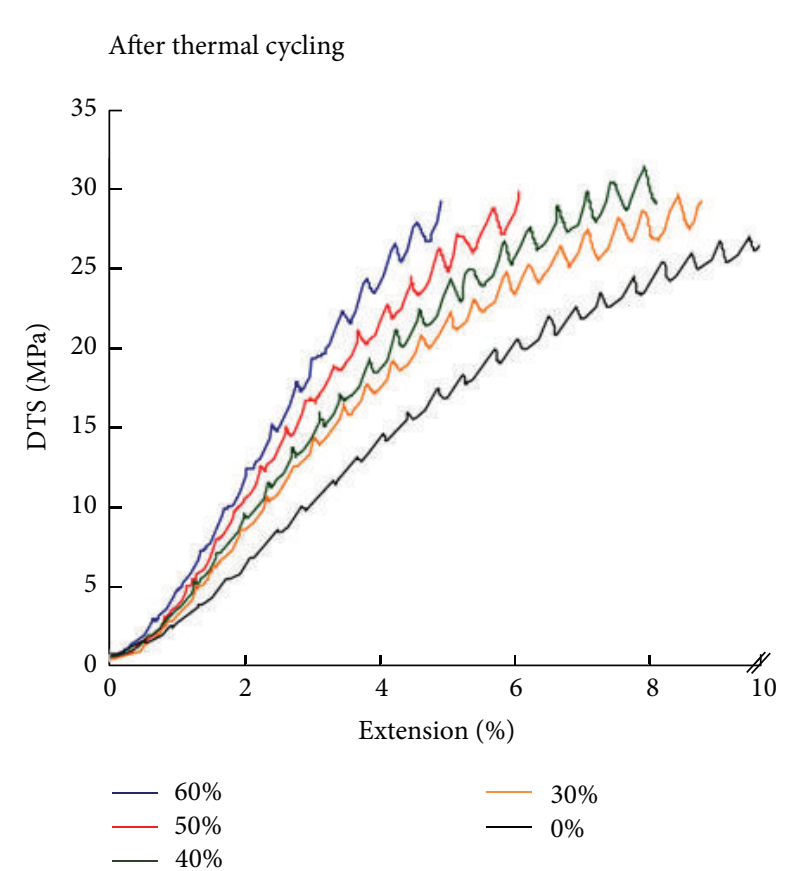

(B)

(b)

FIGURE 2: (a) Resin ultimate strengths (left) and elasticity moduli within $2.0 \%$ offset (right) with various filler amounts before $(\mathrm{A})(P<0.0001)$ and after thermal cycling (B) ( ${ }^{*}$ not significantly different, $P>0.05 ; n=15$ for all data). The strengths were calculated on a maximum stress on deformation curve and moduli were calculated from an inclination of an elastic part on the deformation curves by $2 \%$ offset. (b) Typical curves were shown in relative strengths and deformed ratio to sample diameter (designate as extension \%) with various filler ratios before (A) and after thermal cycling (B).

3.2. Strength Characterization. The mean strength values, DTS standard deviations, and elasticity moduli for the various filler amounts before and after thermal cycling are shown in Figure 2(a). The deformations of specimen with different filler amounts were revealed in Figure 2(b), and as specimens through thermal cycling, the moduli became higher at the same extension values. Statistical analyses revealed that the DTS and elasticity modulus values were significant for all test groups between 30\% and 60\% filler when compared to the no filler resin control $(P<0.0001$, Table 1). Because a significant fracture did not occur during the testing process in the control group, the highest mean DTS value was observed and thus a control group undergoing large plastic deformation without fracture was a nearly ductile 
TABLE 1: One-way ANOVA of different TTCP to whisker-treated filler amounts before and after thermal cycling per sample compared with physical properties $(n=15)$.

\begin{tabular}{llc}
\hline Groups & $\begin{array}{l}P \text {-value } \\
\text { Ultimate DTS during testing }\end{array}$ & $\begin{array}{c}\text { Tukey's pairwise comparison } \\
\text { Variations and group comparisons of control (no } \\
\text { filler) } / 30 / 40 / 50 / 60 \mathrm{wt} \% \mathrm{fillers}\end{array}$ \\
$\quad \begin{array}{l}\text { Before thermal cycling } \\
\text { After thermal cycling }\end{array}$ & $<0.0001^{*}$ \\
$\begin{array}{l}\text { Modulus of elasticity (2\% offset) } \\
\text { Before thermal cycling }\end{array}$ & $\begin{array}{c}\text { Control }>30>40>50=60 \mathrm{wt} \% \mathrm{groups} \\
\text { Control }>30=40=50=60 \mathrm{wt} \% \text { groups }\end{array}$ \\
$\quad \begin{array}{l}\text { After thermal cycling } \\
\text { pH values of immersed solution after } \\
\text { thermal cycling }\end{array}$ & $<0.0001^{*}$ & $60>50>40=30>$ control groups \\
$\begin{array}{l}\text { Testing group comparisons of DTS before } \\
\text { and after thermal cycling }\end{array}$ & $<0.0001^{*}$ & $60>50>40>30>$ control groups \\
$\begin{array}{l}\text { Testing group comparisons of modulus } \\
\text { before and after thermal cycling procedures }\end{array}$ & $<0.0001^{*}$ & $60>50>40>30>$ control groups \\
\end{tabular}

\#a: after thermal cycling; b: before thermal cycling. ${ }^{*}$ Groups are significantly different at $P<0.05$.

material. A larger amount of filler in the resin became more brittle and significantly decreased the DTS before thermal cycling; the DTS decreased linearly with increasing filler from 30 to $60 \mathrm{wt} \%(P<0.0001)$ (Figure 2(a)). Therefore, the lowest DTS value was recorded for the $60 \mathrm{wt} \%$ filler group led to a highest modulus due to a brittle fracture; this group exhibited the least deformation in all testing processes (Table 1 and Figure 2). The elasticity moduli are reflected on the stress-stain curves. The moduli are obtained from the slope of the line where the stress is linearly proportional to strain. The tendency of DTS in given composite resins with filler increasing $(0-60 \%)$ was inversely proportionate to the measured values of modulus.

Statistical analyses postthermal cycling showed significant differences between the control group without filler (0\%) and each of the testing groups (30-60 wt\% fillers, $P<0.0001)$. However, no significant impact on the wet DTS value was observed for groups with 30 to $60 \mathrm{wt} \%$ reinforced fillers $(P>0.05)$; the mean ultimate DTS value declined to approximately $30 \mathrm{MPa}$ in the reinforced groups. A significant difference in modulus was observed for all groups $(P<0.0001)$ with and without thermal cycling; the moduli increased with increasing filler. Overall, the postthermal cycling composite resins became progressively stiffer as the amount of filler increased.

3.3. $p H$ Values after Thermal Cycling. Figure 3 shows the $\mathrm{pH}$ values of the composite resins immersed in deionized water after thermal cycling. The $\mathrm{pH}$ of the immersed control solution was 6.5 , and the $\mathrm{pH}$ slowly increased with increasing filler amount for the 30, 40, and $50 \mathrm{wt} \%$ groups. The $\mathrm{pH}$ largely increased for the $60 \mathrm{wt} \%$ reinforced group. After the whisker-treated TTCP particle fillers were added to the resin matrix, the $\mathrm{pH}$ fell between $7.2(30 \mathrm{wt} \%)$ and 7.8 (60 wt\%). Larger amounts of TTCP filler in composite resins exhibited higher $\mathrm{pH}$ values, implying that increasing the

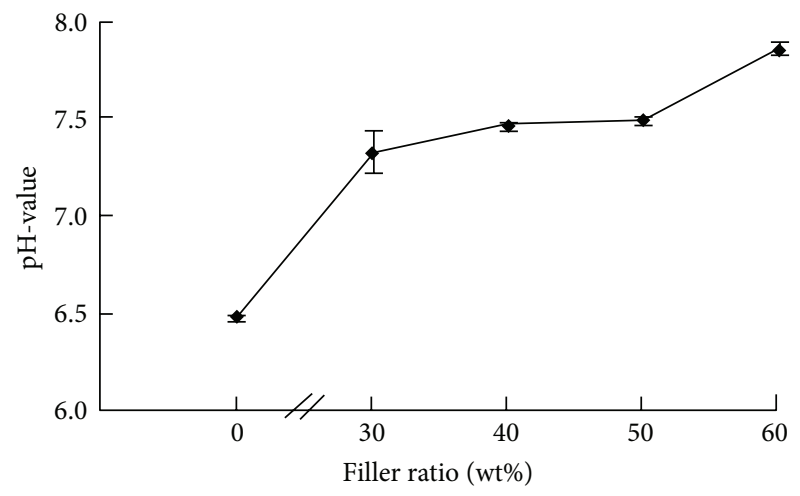

FIGURE 3: The changes in $\mathrm{pH}$ with various filler amounts in the resins after thermal cycling $(n=6)$.

whisker-treated TTCP increased the ion-releasing abilities of the composite resins.

3.4. Microscopic Observation. Under SEM observation and Ca element mapping, a clear interface was observed between the filler and the resin matrix of the reinforcing whiskertreated TTCP filler samples' fractured surfaces, as indicated by the black arrow in Figure 4. This finding suggests poor linkage or incorporation of the additive to the resin matrix before thermal cycling. Once the cracks grew or extended across the resin matrix, they resulted in sample fracturing. The fractured surfaces of the filler-reinforced samples postthermal cycling are also shown in Figure 4. The fractured surface (white arrow, Figure 4) clearly reveals that the anchoring of the filler was not isolated but interlocked closely with the resin matrix. No space between the filler and the matrix was observed, even under higher resolution imaging. The construct was denser, and the combination of the reinforcing whisker-modified TTCP particles and the resin matrix was improved after thermal cycling, reflecting 
Before thermal cycling

Low magnitude/Ca mapping
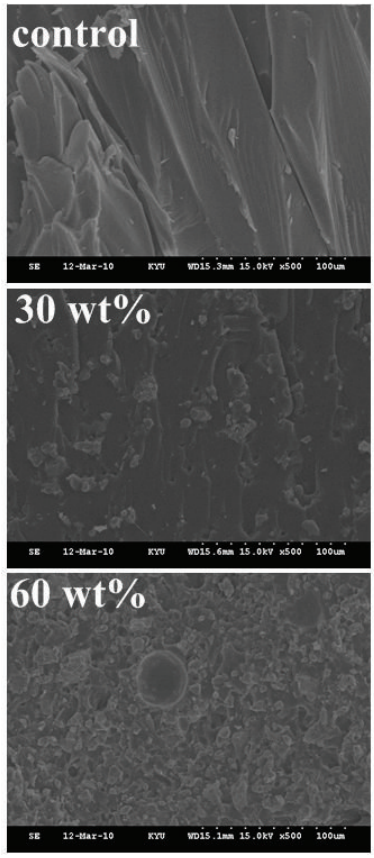

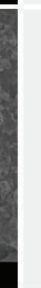

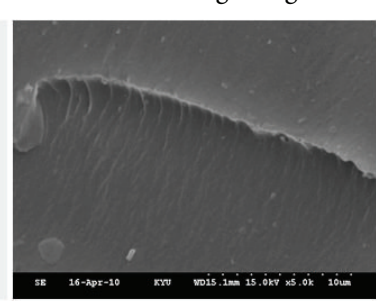
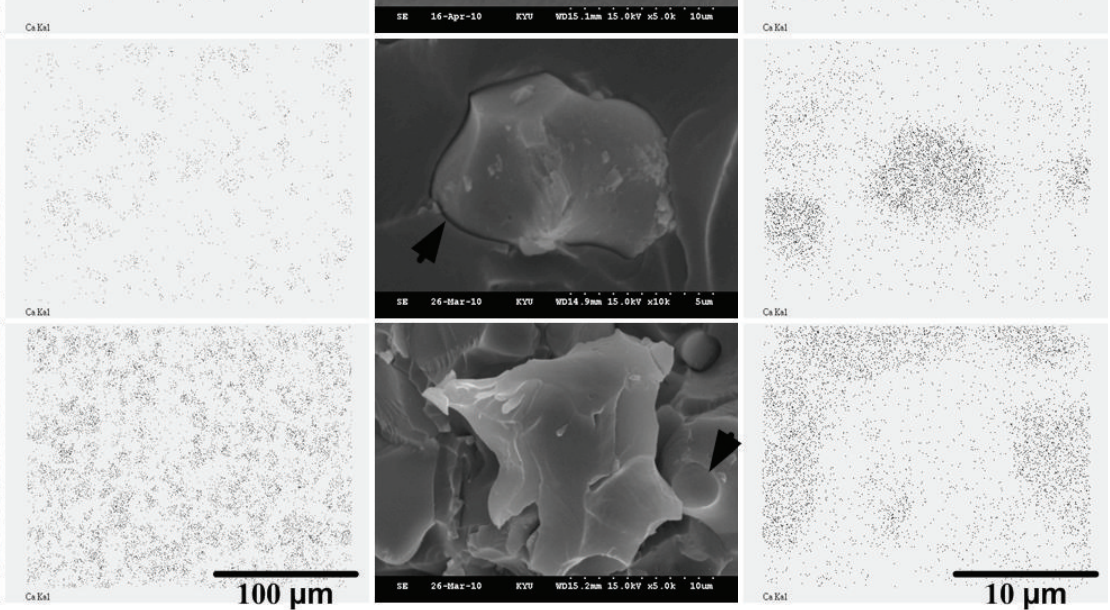

(a)

After thermal cycling
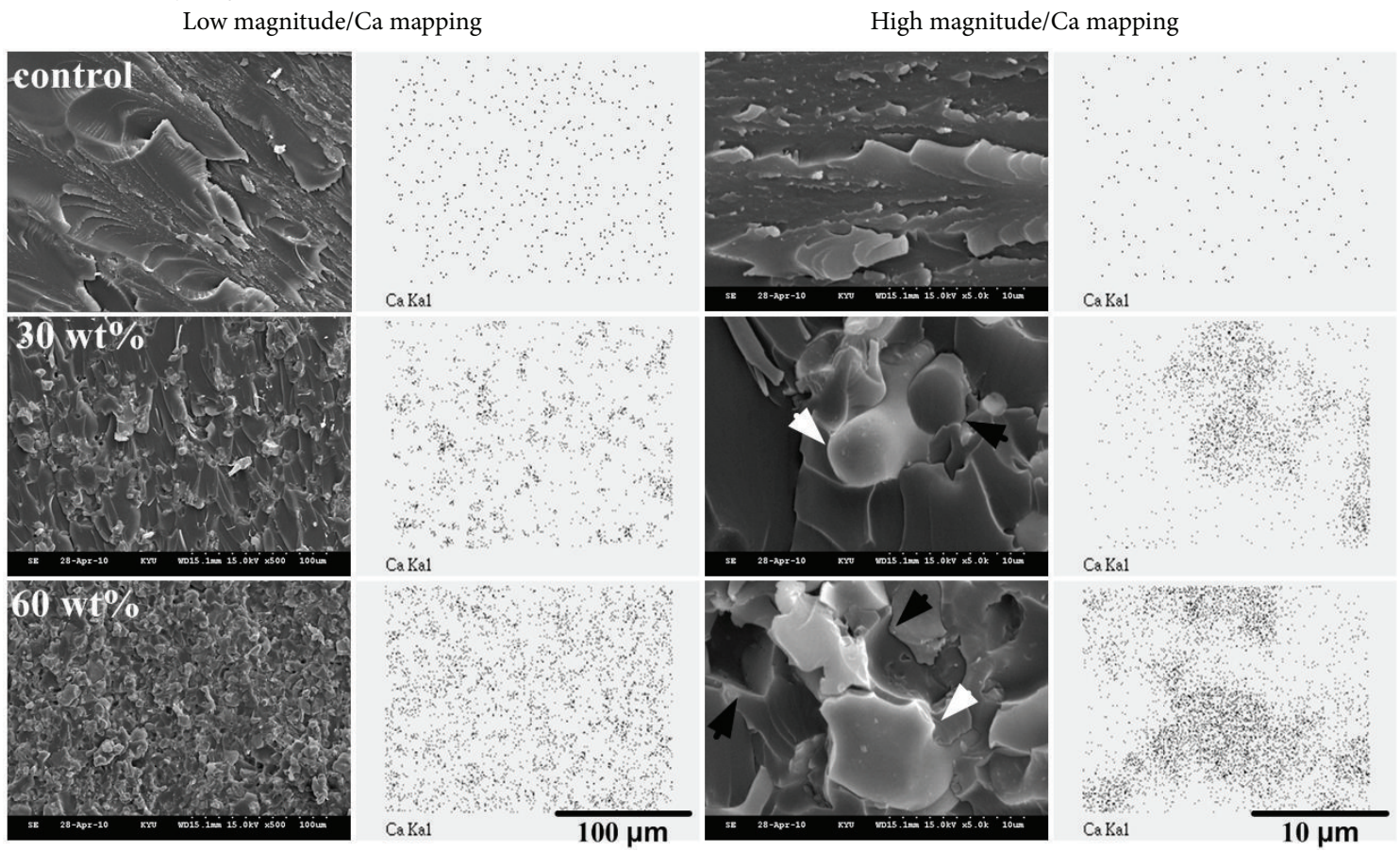

(b)

FIGURE 4: Fractured surfaces of resins with varying ratios of TTCP to whisker-treated filler amounts before and after thermal cycling. The white and black arrows indicate the adhesive and detaching situations of the resin matrix and the TTCP filler reinforcement, respectively. 
the improved strength and elasticity modulus. Contrastingly, a microlinkage was observed between the isolated powder and the resin after DTS testing before thermal cycling. Notably, the control group without filler had significant ductile fracturing patterns, and the same results were observed in the group with $30 \%$ filler. The thermal cycling process was the main factor affecting the mechanical characteristics of the composite resins, converting the ductility of the 40 to $60 \mathrm{wt} \%$ fillers to brittleness and low DTS.

\section{Discussion}

In this study, the tested specimens exhibited DTS values ranging from $31.9 \mathrm{MPa}$ of $30 \mathrm{wt} \%$ fillers to $23.5 \mathrm{MPa}$ of $60 \mathrm{wt} \%$ fillers before thermal cycling. The results are consistent with those of a previous study [25], where the fillers were on the nanometer scale and the dry specimen strengths of amorphous calcium phosphate (ACP) filler composites had DTS values of approximately $20 \mathrm{MPa}$. However, another study measured DTS values between 28 and $33 \mathrm{MPa}$ [23]. Further studies investigated fillers at the micrometer scale and recorded DTS values of $<15 \mathrm{MPa}$. The dimensions and grain size distributions obviously influence the mechanical strength of composite resins [26, 27]. The ability of the anisotropically reinforced composites to disperse forces depends on the contact area of the reinforcements. However, for the comparison of DTS values exhibited no significant scientific effects among various ductile ( $0 \%$ of control group) and brittle substances ( $60 \mathrm{wt} \%$ of fillers), it would be a generalized vale of fracture strength under varied amount fillers. The contact area between the fillers within the resin matrix can be increased by two ways. One method is to increase the filler amount, and the other is to reduce the particle size [28]. In the current study, our strategy was to increase the surface area by growing a thin solid film of nanowhiskers on the particle surfaces. The DTS values declined with increasing filler amount prethermal cycling, possibly suggesting a poor bond between the dispersed phase (filler) and the continuous phase (resin). This poor bond resulted in a lack of reinforcement and subsequent weakening of the composite resins (Figure 4). Particle detachment within the matrix was more evident in the brittle groups than in the ductile group. This weakening effect is consistent with a previous study, which concluded that all the tested ACP fillers yielded polymerized materials that were weaker than unfilled polymers [29].

Adding calcium phosphates to composite resins increases the release of ions available to mineralize between natural teeth and resins, leading to a higher filler mass ratio. Once such resins are exposed to oral fluids, the calcium phosphates make them less sensitive to early water contamination [30]. A study showed that when calcium phosphates are added as fillers in composite resins, the sample hardness, abrasion resistance, and fracture resistance all increase, whereas the polymerization shrinkage and shrinkage stress decrease [31]. In addition, the filler mass ratio of such ion-releasing composites with nanowhiskers improved the bond between the filler and resin matrix. The present study examined the mechanical properties of composite resins in relation to filler hardness and filler concentration in the resin matrix because higher filler hardness and larger filler concentrations tend to result in higher composite resin strengths and brittleness $[32,33]$. TTCP is the only phase with a $\mathrm{Ca} / \mathrm{P}$ molar ratio greater than apatite and exhibits the highest hardness among calcium phosphate substances. TTCP is metastable because it is formed at temperatures higher than $1300^{\circ} \mathrm{C}$, and its synthetic procedures require rapid quenching [34]. The dissolution rate of TTCP is higher than other calcium phosphate substances with $\mathrm{Ca} / \mathrm{P}$ molar ratios of $\geq 1.5$ [35]. Furthermore, when TTCP is used in acidic environments, the nanometer scale of the brushite phase is formed. Due to the dissolution of TTCP, brushite can be instantly converted into apatite nanoparticles/nanowhiskers if the reaction is transferred into a basic solution $[20,36]$. The aforementioned properties of TTCP suggest that it is a potentially efficient remineralizing agent in composite resins. After immersion, whiskers combined with TTCP as a filler in resin have demonstrated strengths two-to three-fold higher than other $\mathrm{Ca}-\mathrm{PO}_{4}$ composites $[12,37]$. The increased strengths are due to the increased surface areas produced by the whiskers, which increase the filler friction against the matrix during pullout, consuming the applied energy [38, 39]. Surface modification of nanowhiskers on the surfaces of TTCP fillers derived from the dissolution/hydrolysis and neutralization reactions yields results different than those of nonmodified TTCP fillers [37, 38]. Accordingly, large filler amounts and higher specific surface areas of fillers in composite resins increase the load dispersion abilities, leading to higher strain resistances under applied loads. This phenomenon is also reflected with the elasticity modulus value increases in the present study.

\section{Conclusions}

The use of calcium phosphate fillers in dental resins as prosthetic substitution materials has been proven to be potentially effective for various clinical applications. Based on the evaluation of mechanical characteristics, such as the ion-releasing ability, strength, and elasticity modulus before and after thermal cycling, composite dental resins with nanowhisker capped TTCP fillers may be promising candidates for novel types of resins with enhanced physical properties. Further studies should focus on the remineralizing effects of whiskertreated TTCP composite resins and the color effects that these materials may have in clinical restorative applications.

\section{Conflict of Interests}

The authors declare that they have no financial or personal relationship with any person or organization that may inappropriately influence their work. There is no professional or commercial interest of any kind in all the commercial identities mentioned in their paper.

\section{Acknowledgments}

The authors acknowledge with appreciation their former plan assistants Ms. Cian-Hua Liou and Hui-Yu Wu and the 
assistance of Dr. Chun-Cheng Hung and Dr. Jen-Chyan Wang in this research. They also acknowledge the major support of the Ministry of Science and Technology, Taiwan, under contract MOST103-2622-E-035-006-CC2, and the partial support plan provided by Alliance Global Technology Co., Ltd., in Kaohsiung Medical Device Special Zone in Southern Taiwan Science Park (EG-32-09-16-101; AZ-10-08-24-102), are likewise appreciated.

\section{References}

[1] D. C. Sarrett, "Clinical challenges and the relevance of materials testing for posterior composite restorations," Dental Materials, vol. 21, no. 1, pp. 9-20, 2005.

[2] K. D. Jandt and B. W. Sigusch, "Future perspectives of resinbased dental materials," Dental Materials, vol. 25, no. 8, pp. 10011006, 2009.

[3] W. C. Chen, C. P. Ju, W. H. Cheng, and J. H. Chernlin, "Green synthesis of calcium and phosphate compounds by varying ph value and $\mathrm{ca} / \mathrm{p}$ atomic ratio using aqueous precipitations," Ceramics-Silikáty, vol. 57, no. 1, pp. 14-21, 2013.

[4] D. Skrtic, A. W. Hailer, S. Takagi, J. M. Antonucci, and E. D. Eanes, "Quantitative assessment of the efficacy of amorphous calcium phosphate/methacrylate composites in remineralizing caries-like lesions artificially produced in bovine enamel," Journal of Dental Research, vol. 75, no. 9, pp. 1679-1686, 1996.

[5] S. H. Dickens, G. M. Flaim, and S. Takagi, "Mechanical properties and biochemical activity of remineralizing resin-based Ca$\mathrm{PO}_{4}$ cements," Dental Materials, vol. 19, no. 6, pp. 558-566, 2003.

[6] S. E. Langhorst, J. N. R. O’Donnell, and D. Skrtic, "In vitro remineralization of enamel by polymeric amorphous calcium phosphate composite: quantitative microradiographic study," Dental Materials, vol. 25, no. 7, pp. 884-891, 2009.

[7] D. Skrtic, J. M. Antonucci, E. D. Eanes, F. C. Eichmiller, and G. E. Schumacher, "Physicochemical evaluation of bioactive polymeric composites based on hybrid amorphous calcium phosphates," Journal of Biomedical Materials Research, vol. 53, no. 4, pp. 381-391, 2000.

[8] H. Wang, M. Zhu, Y. Li, Q. Zhang, and H. Wang, "Mechanical properties of dental resin composites by co-filling diatomite and nanosized silica particles," Materials Science and Engineering $C$, vol. 31, no. 3, pp. 600-605, 2011.

[9] V. P. Feitosa, A. P. Fugolin, A. B. Correr et al., "Effects of different photo-polymerization protocols on resin-dentine $\mu$ TBS , mechanical properties and cross-link density of a nanofilled resin composite," Journal of Dentistry, vol. 40, no. 10, pp. 802-829, 2012.

[10] H. H. K. Xu, M. D. Weir, and L. Sun, "Nanocomposites with Ca and $\mathrm{PO}_{4}$ release: effects of reinforcement, dicalcium phosphate particle size and silanization," Dental Materials, vol. 23, no. 12, pp. 1482-1491, 2007.

[11] H. H. K. Xu, L. Sun, M. D. Weir, S. Takagi, L. C. Chow, and B. Hockey, "Effects of incorporating nanosized calcium phosphate particles on of properties of whisker-reinforced dental composites," Journal of Biomedical Materials Research B: Applied Biomaterials, vol. 81, no. 1, pp. 116-125, 2007.

[12] M. Wang, L. Yang, C. Yu, and C. Xu, "Liquid poly(silylacetylene)siloxane resin as a novel precursor of silicon carbide and silicon oxycarbide ceramics," Ceramics International, vol. 38, no. 3, pp. 2449-2454, 2012.
[13] E. Bernardo, G. Parcianello, and P. Colombo, "Novel synthesis and applications of yttrium silicates from a silicone resin containing oxide nano-particle fillers," Ceramics International, vol. 38, no. 7, pp. 5469-5474, 2012.

[14] W. C. Chen, C. P. Ju, W. H. Cheng, and J. H. Chern Lin, "Carbon black sintering effects on the composition of multiphase calcium phosphate bioceramics," Journal of Ceramic Processing Research, vol. 14, no. 3, pp. 279-283, 2013.

[15] R. M. Felfel, I. Ahmed, A. J. Parsons, G. Palmer, V. Sottile, and C. D. Rudd, "Cytocompatibility, degradation, mechanical property retention and ion release profiles for phosphate glass fibre reinforced composite rods," Materials Science and Engineering C, vol. 33, no. 4, pp. 1914-1924, 2013.

[16] W. C. Chen, C. P. Ju, and J. H. C. Lin, "Effect of heat treatment on compressive strength and setting behavior of TTCP/DCPAderived calcium phosphate cement," Journal of Materials Science Letters, vol. 21, no. 20, pp. 1583-1585, 2002.

[17] K. M. Burger, R. L. Cooley, and F. Garcia-Godoy, "Effect of thermocycling times on dentin bond strength.," Journal of Esthetic Dentistry, vol. 4, no. 6, pp. 197-198, 1992.

[18] S. Elekdag-Turk, T. Turk, D. Isci, and N. Ozkalayci, "Thermocycling effects on shear bond strength of a self-etching primer," Angle Orthodontist, vol. 78, no. 2, pp. 351-356, 2008.

[19] W. C. Chen and H. Y. Wu, "Color stability of nanocrystallitetreated and silicate-treated fillers of calcium phosphate composite resin: an in vitro study," The Journal of Prosthetic Dentistry, vol. 111, no. 5, pp. 416-424, 2014.

[20] J. Wang, C. Ko, C. Hung et al., "Deriving fast setting properties of tetracalcium phosphate/dicalcium phosphate anhydrous bone cement with nanocrystallites on the reactant surfaces," Journal of Dentistry, vol. 38, no. 2, pp. 158-165, 2010.

[21] W. E. Brown and E. F. Epstein, "Crystallography of tetracalcium phosphate," Journal of Research of the National Bureau of Standards A, vol. 69, no. 6, pp. 547-551, 1965.

[22] S. H. Dickens-Venz, S. Takagi, L. C. Chow, R. L. Bowen, A. D. Johnston, and B. Dickens, "Physical and chemical properties of resin-reinforced calcium phosphate cements," Dental Materials, vol. 10, no. 2, pp. 100-106, 1994.

[23] I. S. Medeiros, M. N. Gomes, A. D. Loguercio, and L. E. R. Filho, "Diametral tensile strength and Vickers hardness of a composite after storage in different solutions," Journal of Oral Science, vol. 49, no. 1, pp. 61-66, 2007.

[24] W. Lien and K. S. Vandewalle, "Physical properties of a new silorane-based restorative system," Dental Materials, vol. 26, no. 4, pp. 337-344, 2010.

[25] J. N. R. O’Donnell, D. Skrtic, and J. M. Antonucci, “Amorphous calcium phosphate composites with improved mechanical properties," Journal of Bioactive and Compatible Polymers, vol. 21, no. 3, pp. 169-184, 2006.

[26] Y. Matsuya, J. M. Antonucci, S. Matsuya, S. Takagi, and L. C. Chow, "Polymeric calcium phosphate cements derived from poly(methyl vinyl ether-maleic acid)," Dental Materials, vol. 12, no. 1, pp. 2-7, 1996.

[27] R. M. Khashaba, M. Moussa, C. Koch et al., "Preparation, physical-chemical characterization, and cytocompatibility of polymeric calcium phosphate cements," International Journal of Biomaterials, vol. 2011, Article ID 467641, 13 pages, 2011.

[28] S. Ramakrishna, J. Mayer, E. Wintermantel, and K. W. Leong, "Biomedical applications of polymer-composite materials: a review," Composites Science and Technology, vol. 61, no. 9, pp. 1189-1224, 2001. 
[29] D. Skrtic, J. M. Antonucci, and E. D. Eanes, "Improved properties of amorphous calcium phosphate fillers in remineralizing resin composites," Dental Materials, vol. 12, no. 5-6, pp. 295-301, 1996.

[30] M. O. Mante, N. Saleh, N. K. Tanna, and F. K. Mante, "Softening patterns of light cured glass ionomer cements," Dental Materials, vol. 15, no. 5, pp. 303-309, 1999.

[31] M.-H. Chen, "Critical reviews in oral biology \& medicine: update on dental nanocomposites," Journal of Dental Research, vol. 89 , no. 6, pp. 549-560, 2010.

[32] J. R. M. D'Almeida and S. N. Monteiro, "The resin/hardener ratio as a processing parameter for modifying the mechanical behaviour of epoxy-matrix/glass microsphere composites," Composites Science and Technology, vol. 58, no. 10, pp. 15931598, 1998.

[33] Y. Li, Q. Chen, M. Yi et al., "Effect of surface modification of fiber post using dopamine polymerization on interfacial adhesion with core resin," Applied Surface Science, vol. 274, no. 1, pp. 248-254, 2013.

[34] C. Moseke and U. Gbureck, "Tetracalcium phosphate: synthesis, properties and biomedical applications," Acta Biomaterialia, vol. 6, no. 10, pp. 3815-3823, 2010.

[35] P. Ducheyne, S. Radin, and L. King, "The effect of calcium phosphate ceramic composition and structure on in vitro behavior. I. Dissolution," Journal of Biomedical Materials Research, vol. 27, no. 1, pp. 25-34, 1993.

[36] U. Gbureck, T. Holzel, R. Thull, F. A. Muller, and J. E. Barralet, "Preparation of nanocrystalline hydroxyapatite scaffolds by 3D powder printing," Cytotherapy, vol. 8, no. 14, supplement 2, article 46, 2006.

[37] W. Chen, H. Wu, and H. Chen, "Evaluation of reinforced strength and remineralized potential of resins with nanocrystallites and silica modified filler surfaces," Materials Science and Engineering C, vol. 33, no. 3, pp. 1143-1151, 2013.

[38] C. Canal and M. P. Ginebra, "Fibre-reinforced calcium phosphate cements: a review," Journal of the Mechanical Behavior of Biomedical Materials, vol. 4, no. 8, pp. 1658-1671, 2011.

[39] F. Wang, L. Shi, W. He et al., "Bioinspired micro/nano fabrication on dental implant-bone interface," Applied Surface Science, vol. 265 , no. 15, pp. 480-488, 2013. 

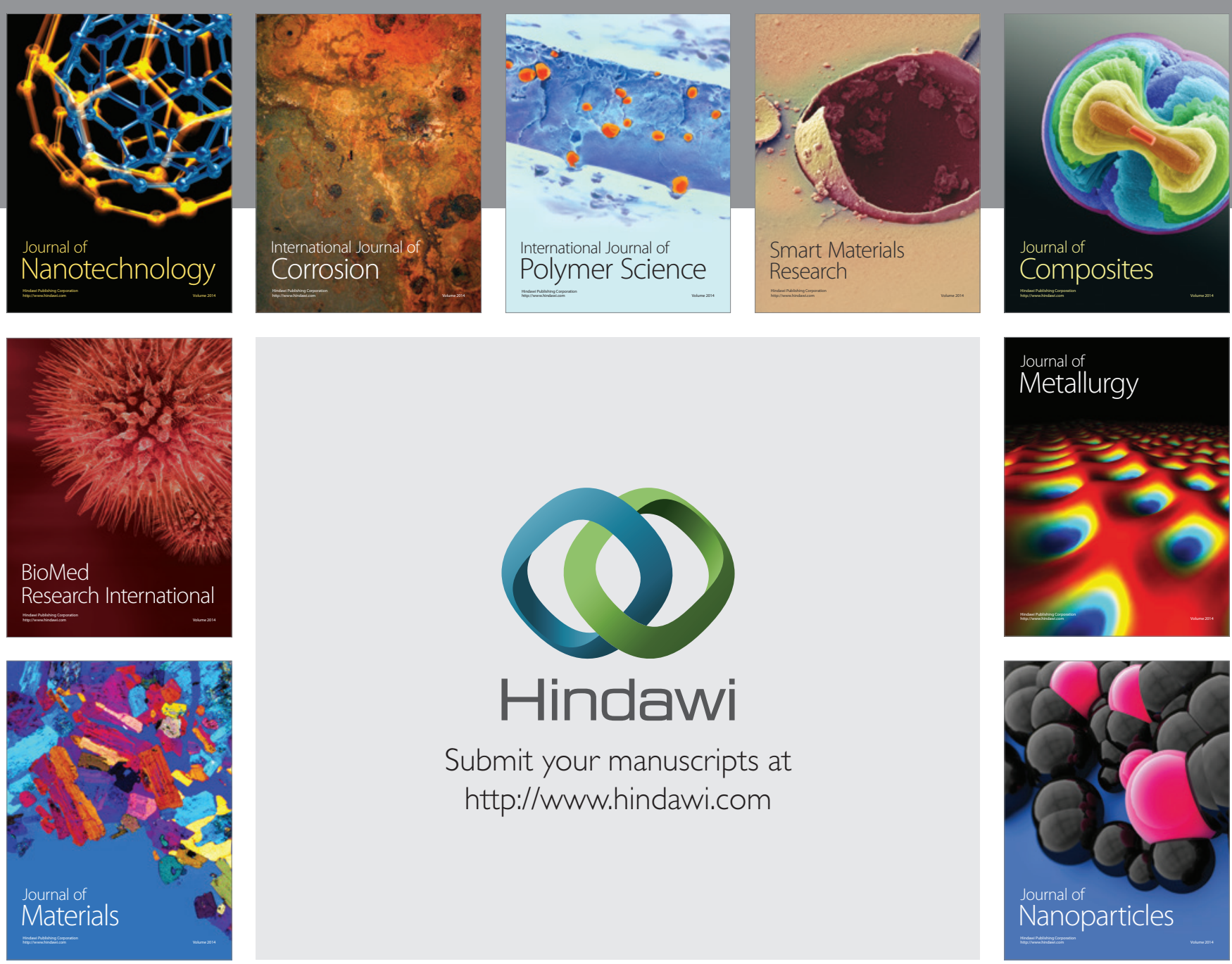

Submit your manuscripts at http://www.hindawi.com
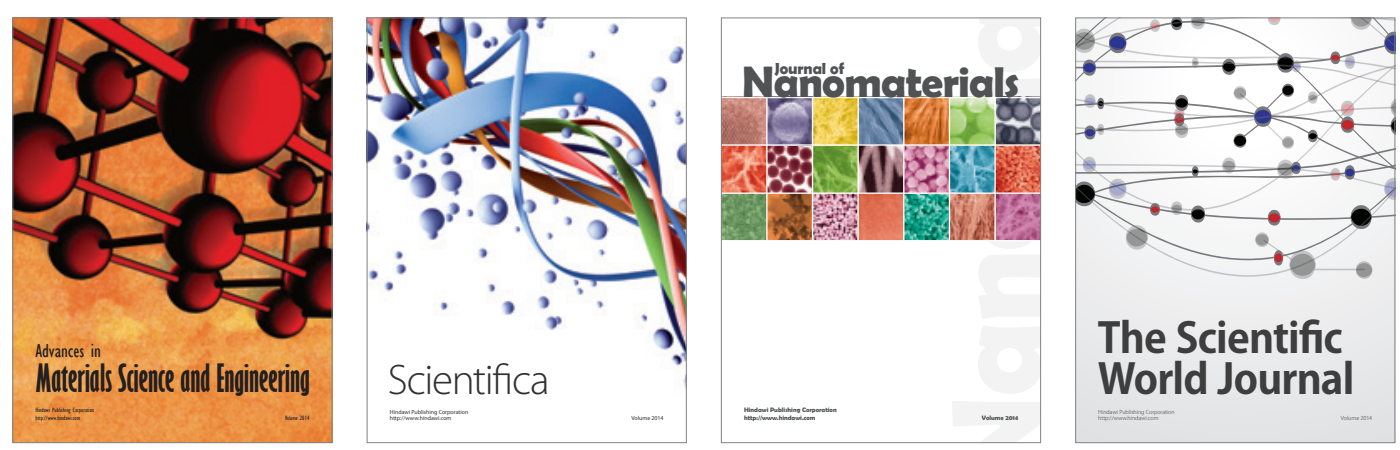

\section{The Scientific World Journal}
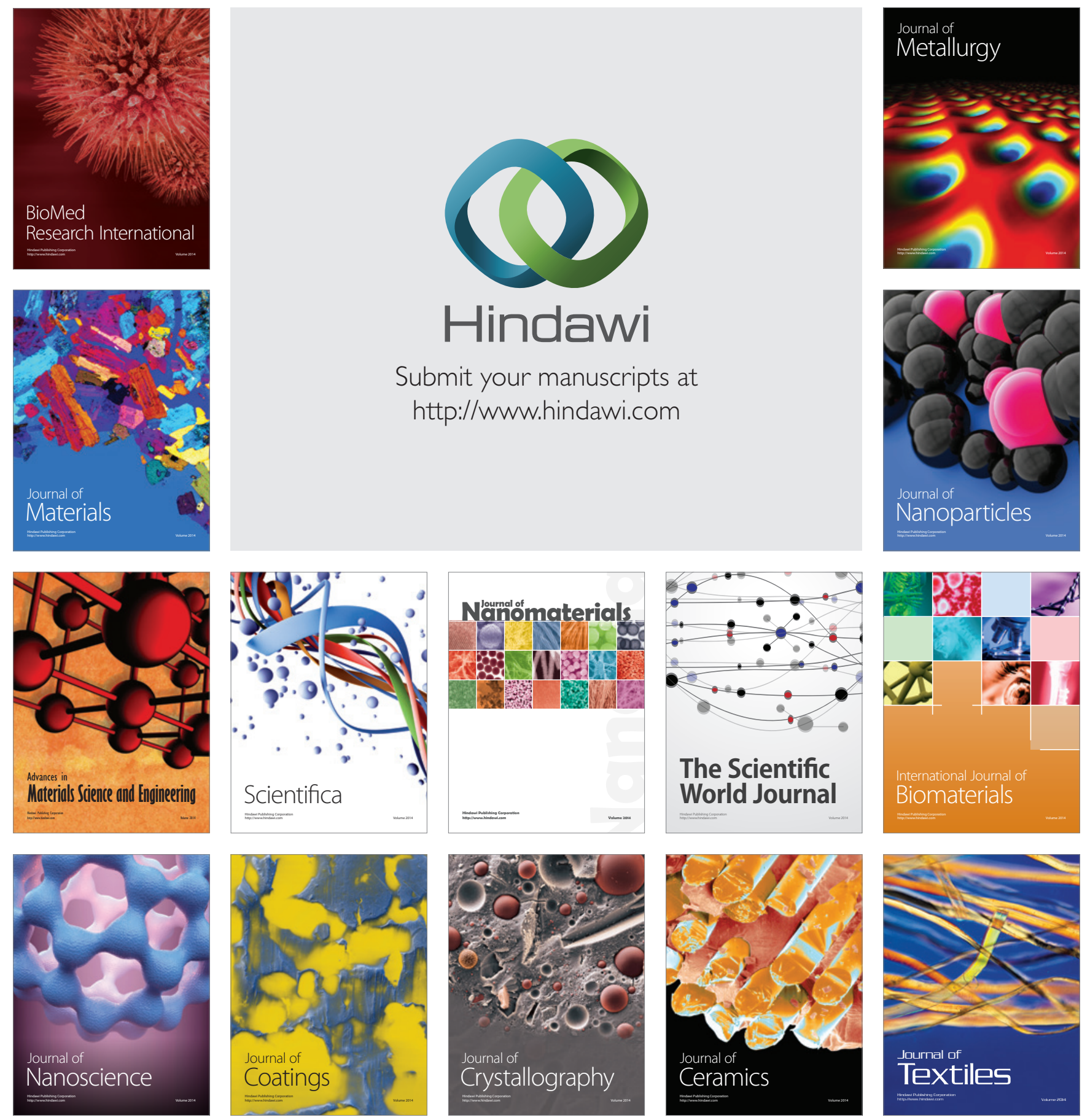